\title{
A conceptual model to explain strategic alignment in the financial services based on Balanced Scorecard
}

\author{
Mohammad Safari \\ Faculty of Management, University of Tehran, Tehran, Iran \\ E-mail address: m.safari@ut.ac.ir
}

\begin{abstract}
The lack of alignment of organization elements towards the organizational strategy leads to poor execution. When the different departments of the organization have different strategies that are different directions and implementations, the whole organizational purposes and visions rarely could archive. The main purpose of this research is to present a valuable approach for success organizations that we named strategic alignment. For this purpose we use the Balanced Scorecard (BSC). The Balanced Scorecard is a management tool used to translate the corporate strategic mission and vision into a set of quantifiable indicators of performance. In other words, it is intended to explain what to do and how to do it. The real contribution of a Balanced Scorecard program is to link the objectives in each of four perspectives: financial, processes, customers, and growth and learning. In this study using a valid questionnaire and also with focus group method the final theoretical research model was presented. Results of this research showed that BSC is a useful tool and has high validity and reliability for strategic alignment for financial organizations. The results are applicable for both academicians and practitioners for managing strategies and related programs and tactics in the financial institutions and organizations.
\end{abstract}

Keywords: strategic alignment; Balanced Scorecard (BSC); financial services; Iranian banking sector

\section{INTRODUCTION}

No organization exists without a purpose. They are free to pursue their chosen course so long as they also fulfill certain expectations of their environment. Purpose provides the framework for strategy formation, which is the basis for strategy implementation. It is expected that people direct their efforts and activities towards implementing projects or initiatives aimed at accomplishing their purpose; however, many organizations suffer from a lack of adequate coordination and focused execution. Studies have shown that, in most organizations, strategy management is a dismal art. A high percentage of strategic plans do not get implemented. Many employees have a short- term perspective regarding the future of the organization making it very difficult for them to align their priorities and activities. Strategic planning efforts are frequently not designed, deployed, and controlled in such a way as to align employee's efforts towards organizational goals (Olascoaga, 2008). So strategic alignment is extraordinary important for organizations that intend to gain sustainable advantage in the today turbulent markets. On the other hand, the Balanced Scorecard is a strategic management tool and performance measurement system designed to directly translate an organization's strategies into action-oriented plans. The BSC was created by 
Robert Kaplan and David Norton in 1992 and has rapidly gained popularity because it offers the opportunity to control organizational performance with a measurement system based on organizational perspectives rather than traditional accounting perspectives. Intensive research has been done to assess the benefits associated with the applications of the BSC in industry. The more recent research efforts will be highlighted in the literature review (Andersen, 2004).

The changing environments, forces, and threats that organizations are facing in translating strategies into action-oriented plans to be executed have, however, introduced some failures. Gupta (Gupta, 2004) made a point about certain realities in the applications of BSC when he explained that the design measurement process could be so long and bothersome that it could result in an immense amount of performance indicators that are not actually related to the organization's goals. So, the main research question for this study is: how can help organizations in the financial industry to align strategies with focus on Banking Sector in Iran? Thus, the main purpose of this study is to address financial organizations to achieve strategic alignment by using Balanced Scorecard.

\section{STRATEGIC ALIGNMENT}

The word alignment is widely used without an accepted operational definition. The word itself may be used in slightly different ways. Alignment is defined in dictionaries as "the act of adjusting to a line; a formation in a straight line" (Porter, 1996). Or the process of adjusting parts so that they are in proper relative position. In another perspective alignment is defined as an organization of people involved in a pact or treaty (Yuksel, \& Dagdeviren, 2007). Fonvielle and Cart (Kangas et al, 2003) suggest that alignment is not only a matter of individuals agreeing on goals and means; it also refers to the need for business processes and functions to rally their actions around the flagpole of the organization's strategy. Strategic alignment has many pseudonyms. It is also termed fit, integration, bridge, harmony, fusion and linkage. However, in all cases, it concerns the integration of strategies relating to the business and it's IT/IS. There are those who argue that IS alignment is not an issue in its own right. Some researchers, for example, Smaczny (Rodriguez, 2008), assert that as "IS" is pervasive in business, it should not be regarded as separable from business strategy, and therefore the need for alignment does not arise. Smaczny uses the term fusion to describe this integration. Yet, strategy in its broadest sense is all about alignment or matching organizational resources (including IS) with environmental threats and opportunities (Thompson et al, 2001). Indeed, IT management can be conceptualized as a problem of aligning the relationships between the business and IT infrastructure domain in order to take advantage of IT opportunities and capabilities. So, in the next section steps of strategic management and planning will describe and on this basis strategic alignment will presented.

\section{STRATEGIC PLANNING AND MANAGEMENT}

The global economic landscape and business world are changing rapidly. Strategic management in turbulent conditions needs to be pro-active. Just when managers think they have developed a strategy for future success, a new technology, process, competitor or customer behavioral pattern emerges. While a sharp focus and "sticking to the knitting" is sometimes the key to success in more stable conditions, the turbulent, knowledge-driven markets of today require dynamic new strategic management approaches and tools. 
In today's highly competitive business environment, budget-oriented planning or forecast-based planning methods are insufficient for a large corporation to survive and prosper. The firm must engage in strategic planning that clearly defines objectives and assesses both the internal and external situation to formulate strategy, implement the strategy, evaluate the progress, and make adjustments as necessary to stay on track (Teece et al, 1997).

\section{- Mission and Objectives}

The mission statement describes the company's business vision, including the unchanging values and purpose of the firm and forward-looking visionary goals that guide the pursuit of future opportunities. Guided by the business vision, the firm's leaders can define measurable financial and strategic objectives. Financial objectives involve measures such as sales targets and earnings growth. Strategic objectives are related to the firm's business position, and may include measures such as market share and reputation (Ayuso et al, 2006).

\section{- Environmental Scanning}

The environmental scan includes the following components:

$>$ Internal analysis of the firm

$>$ Analysis of the firm's industry (task environment)

$>$ External macro-environment

The internal analysis can identify the firm's strengths and weaknesses and the external analysis reveals opportunities and threats. A profile of the strengths, weaknesses, opportunities, and threats is generated by means of a SWOT analysis. An industry analysis can be performed using a framework developed by Michael Porter known as Porter's five forces. This framework evaluates entry barriers, suppliers, customers, substitute products, and industry rivalry.

\section{- Strategy Formulation}

Given the information from the environmental scan, the firm should match its strengths to the opportunities that it has identified, while addressing its weaknesses and external threats.

To attain superior profitability, the firm seeks to develop a competitive advantage over its rivals. A competitive advantage can be based on cost or differentiation. Michael Porter identified three industry-independent generic strategies from which the firm can choose.

\section{- Strategy Implementation}

The selected strategy is implemented by means of programs, budgets, and procedures. Implementation involves organization of the firm's resources and motivation of the staff to achieve objectives. The way in which the strategy is implemented can have a significant impact on whether it will be successful. In a large company, those who implement the strategy likely will be different people from those who formulated it. For this reason, care must be taken to communicate the strategy and the reasoning behind it. Otherwise, the implementation might not succeed if the strategy is misunderstood or if lower-level managers resist its implementation because they do not understand why the particular strategy was selected (Lawson, B., Samson, 2001). 


\section{- Evaluation \& Control}

The implementation of the strategy must be monitored and adjustments made as needed. Evaluation and control consists of the following steps:

$>$ Define parameters to be measured

$>$ Define target values for those parameters

$>$ Perform measurements

$>$ Compare measured results to the pre-defined standard

$>$ Make necessary changes

The strategy literature has long proposed that firms' competitive business strategies must suit their environmental circumstances (Chen, C. and Jaw, 2009). Such strategies focus on how firms compete with, and position themselves in relation to competitors. The Western literatures have proposed a number of typologies for classifying firm-level competitive strategies. Building upon the earlier frameworks, Gupta and Govindarajan suggest that firms' strategies can be placed on a growth continuum. At one end are firms following a "pure build" strategy that focuses on attaining growth by improving market share and competitive position at the expense of short- term performance. At the other end are firms following a "pure harvest" strategy, with a focus on maximizing short-term profit and cash flow rather than growth and market share. In the middle are firms that seek to hold their current positions or divest away peripheral operations. The challenge for strategic management is to develop frameworks to understand how new levels of order (innovative business models and new industries) emerge, and how one can enable them to emerge from complex, seemingly chaotic patterns of interaction in socio-cultural business systems. It is, furthermore, essential to understand the properties (or configurations) of these emergent business models in terms of their resilience to perturbation and their capacity for self-maintenance. According to Norman, continuous improvement of an existing business model often becomes a trap from which companies fail to see that the rules of the game are changing faster than the company, or that the game has changed altogether. As stated in the previous chapter, the new strategic management paradigm now becomes systemic strategic management: co-shaping of organizational value propositions through systemic organizational capabilities. The organization's role is now changing from being viewed as a value-providing entity in particular industry value-chains, just "fitting" reactively into value-chain configurations, to being a co-shaping organizer of value creation that may lead to new industry configurations.

\section{BALANCED SCORECARD}

The Balanced Scorecard is a management tool used to translate the corporate strategic mission and vision into a set of quantifiable indicators of performance. In other words, it is intended to explain what to do and how to do it. The real contribution of a Balanced Scorecard program is to link the objectives in each of four perspectives: financial, processes, customers, and growth and learning. BSC focuses on four basic concepts: Performance at the Business Units (BU) level, cause-and-effect relationships, both non-financial and financial measurements, and dissemination of corporate strategies to employees. The Balanced Scorecard is best deployed at the strategic level and trickled down through the organization. 


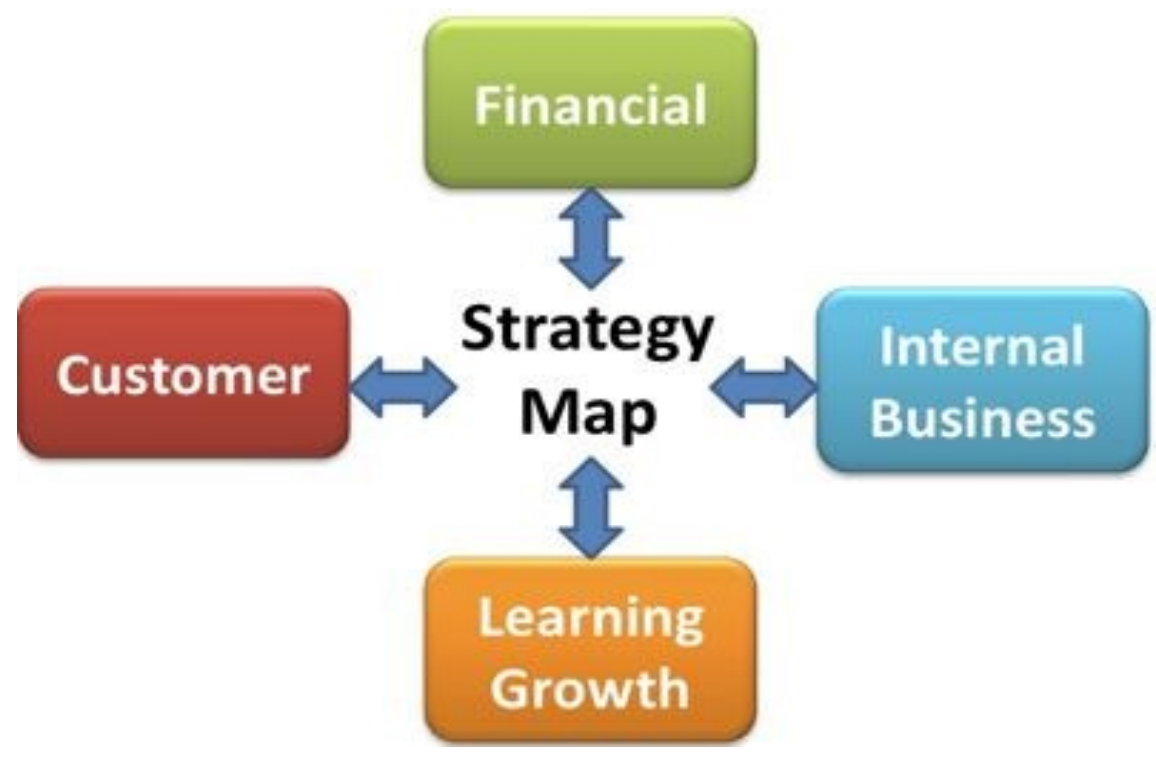

Figure 1. Four basic dimensions of strategy map.

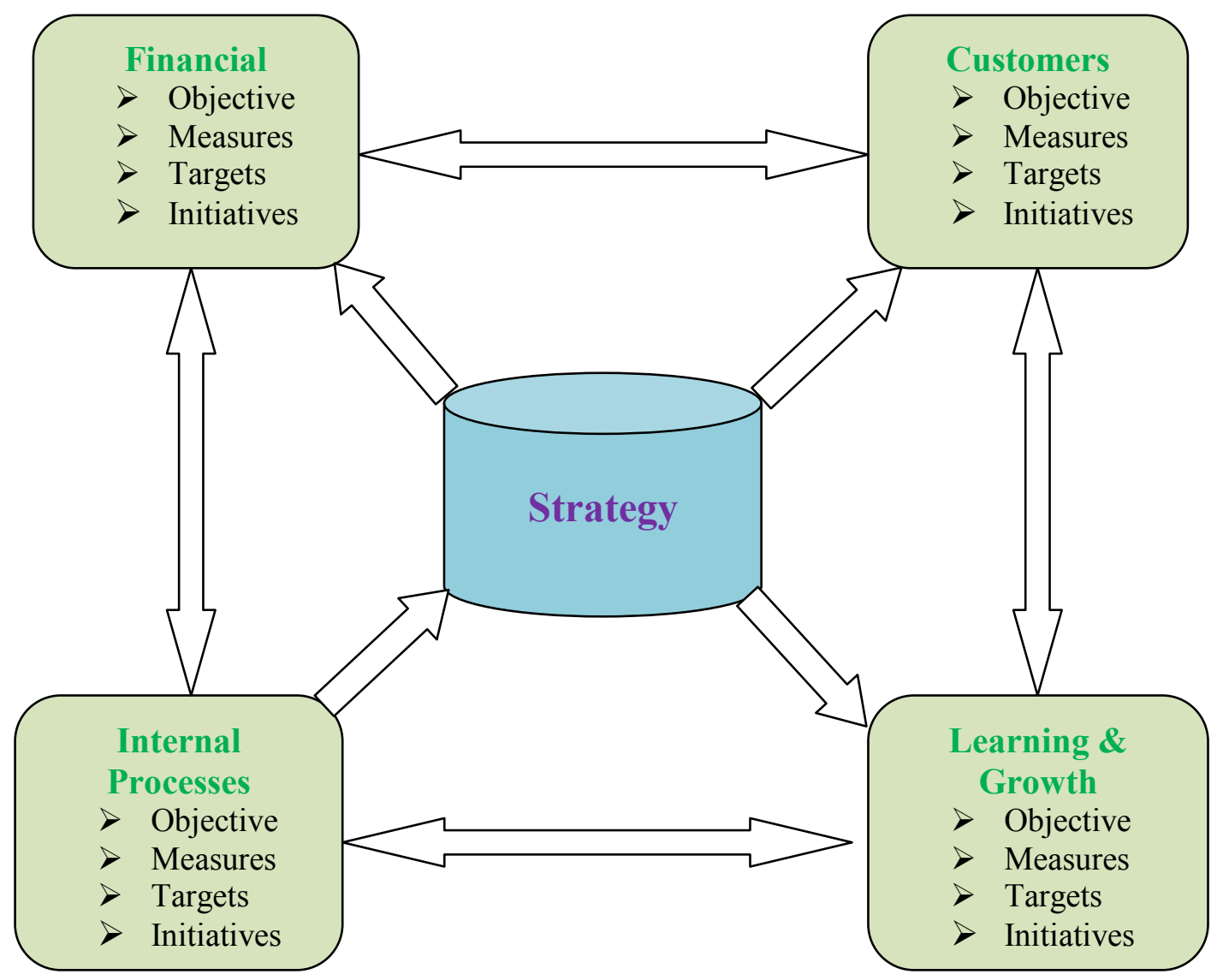

Figure 2. Basic dimensions of BSC based on its sub-criterias. 
Work groups can devise their own Balanced Scorecards and their corresponding BUs that show their contribution to the strategy of the organization. Action plans and resource allocation can be determined according to the work groups' contributions to the corporate Balanced Scorecard objectives.

According to Kaplan and Norton, there are four basic perspectives that creating the strategy map. Figure 1 shows this framework.

The balanced scorecard strives to create a balance between various main dimensions and also performance areas of an organization or firm.

When Financial, Customer, Business Processes and Learning and Growth measures are presented together, as in Figure below, the BSC allows managers to view the organization from several perspectives simultaneously

The BSC approach recognizes the fact that goals can vary from BU to BU, so performance measurement should be adapted to a specific environment. While implementing a Balanced Scorecard, managers articulate their strategy for the organization. Department personnel go through training and attend sessions to develop the vision, strategy, and measurements that will lead to a Balanced Scorecard.

Departments develop objectives and targets as well as action plans (Safari-Kahreh et al, 2014).

\section{- Competitive Intelligence}

Over the past two decades, competitive intelligence (CI) has grown from a small area of interest into an internationally recognized and practiced. CI is not just market research [36] or business scanning. $\mathrm{CI}$ is a process of knowing what the competition is up to and staying one step ahead of them, be gathering information about competitors and, ideally applying it short and long-term strategic planning (Safari-Kahreh et al, 2014).

\section{- Dynamic Capabilities}

In the last decade, the notion of dynamic capabilities as the ultimate source of competitive advantage has catapulted these concepts to the forefront of strategy research. Dynamic capabilities reflect an organization's ability to derive new and innovative forms of competitive advantage based on distinctive managerial and organizational processes, the firm's specific asset position, and the evolutionary path it follows.

Lawson and Samson applied a dynamic capabilities approach to the investigation of innovation.

\section{DESIGN AND METHODOLOGY}

The method of this research are Applied Research in goal, and in the view point of data gathering is Descriptive-Analytic, non-experimental, that is implemented with the case study format. The case study of this research is Banking Sector of Iran. In this study, by reviewing with experts, the proposed research model will examined and the final research model in the end of the research will presented.

For this purpose required data has been gathered from experts using questionnaire. Total of filled questionnaires were 55. The experts of this research are both academicians and professionals of the field. The characteristics of research population including experts are as follow: 
Table 1. Descriptive characteristics of case of the research (Gender).

\begin{tabular}{|c|c|c|}
\hline Variables & Frequency & Percent \\
\hline Gender & 44 & 80 \\
Male & 11 & 20 \\
Female & & \\
\hline Work area & 38 & 69 \\
Academician & 17 & 31 \\
Practitioner & 55 & 100 \\
\hline Total & & \\
\hline
\end{tabular}

\section{1. Validity and Reliability}

Validity and reliability are two necessary features for every measuring material such as questionnaire because these materials should analyze data and provide final conclusions for researchers. To sum up, validity means that a measuring material is used to measure the characteristics. A questionnaire was used for data collection. Questions were evaluated by the Likert 5-choice measurement. Cronbach's Alpha Coefficient was used to measure reliability. The average of Cronbach's alpha for 5 basic elements and categories of this research was 0.87 that is more than the mean acceptable alpha. Hence, the questionnaire was reliable. First, reliability of the questions was evaluated. Table 2 shows the results (Alpha Cronbach is used to test the reliability of the materials used in the research). All these parts bear high reliability $(a>0.7)$. Also, validity of this questionnaire, because this instrument was unique and for gathering data was used in this research, was meet by means of experts insights and then examine and analysis of those.

Table 2. Results of Reliability test.

\begin{tabular}{|c|c|c|}
\hline $\begin{array}{c}\text { Basic Elements and } \\
\text { Categories }\end{array}$ & $\begin{array}{c}\text { Calculated Cronbach's } \\
\text { Alpha }\end{array}$ & Total of questions \\
\hline Environmental Scanning & 0.788 & 3 \\
Strategic Formulation & 0.809 & 4 \\
Strategic Implementation & 0.897 & 3 \\
Balanced Scorecard & 0.755 & 2 \\
Applicability & 0.845 & 15 \\
\hline Total & 0.870 & \\
\hline
\end{tabular}

\section{RESEARCH ANALYTICAL MODEL}

Based on above description, the proposed research model for strategic alignment in the financial services with focus on Banking Sector, are presented in this section. For align strategies in the financial services we use balanced scorecard. Using BSC provide 
organizations to capture four essential departments by means of: financial, customers, learning and growth and internal processes criteria. Figure 3 will show the proposed research model.

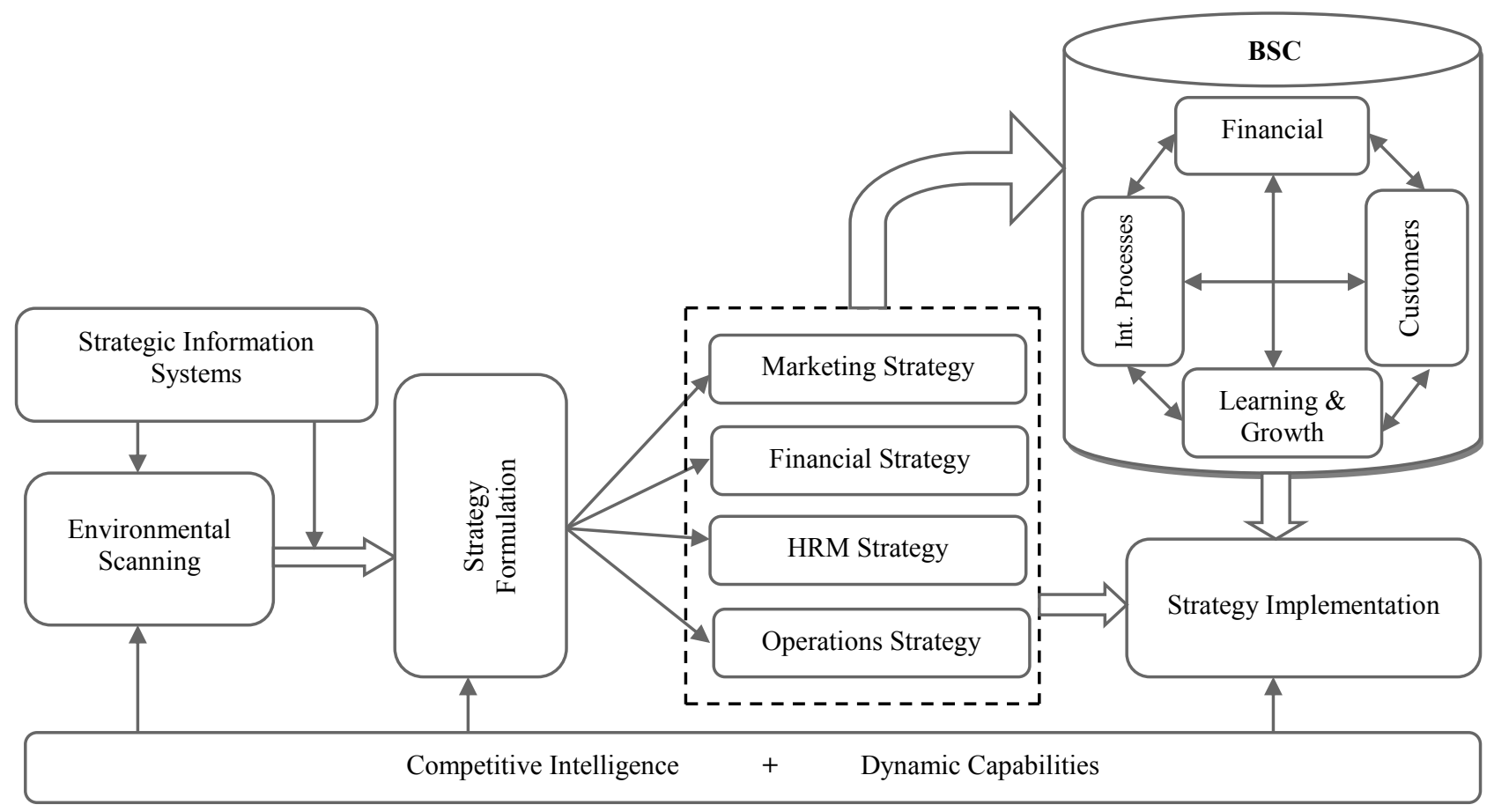

Figure 3. The Research Analytical Model

\section{ANALYSIS}

In this section the affectability and importance of research elements are analyzed. For this purpose the 17 hypotheses are formed that showed in the Table 3 . These hypotheses associated with the four major steps of strategic management and planning and also including competitive intelligence and dynamic capabilities. The results of data analysis are showed in the Table 3. The results mainly show that BSC is strongly affect on strategy implementation and is strong tool for align organizational strategies in the financial services.

Figure 3. The results of one-sample t-test for investigate the hypotheses

\begin{tabular}{|c|c|c|c|c|c|c|}
\hline Hypotheses & t-statistics & d.f & Sig & Mean & t-value & Confirm / Reject \\
\hline H1 & 11.002 & 249 & 0.000 & 2.035 & 3 & Confirmed \\
\hline H2 & 10.998 & 249 & 0.000 & 2.803 & 3 & Confirmed \\
\hline H3a & 12.450 & 249 & 0.000 & 1.076 & 3 & \\
H3b & 10.135 & 249 & 0.000 & 3.003 & 3 & Confirmed \\
H3c & 11.354 & 249 & 0.000 & 2.112 & 3 & \\
H3d & 10.987 & 249 & 0.000 & 1.889 & 3 & Confirmed \\
\hline H4a & 8.125 & 249 & 0.000 & 2.006 & 3 & \\
H4b & 9.430 & 249 & 0.000 & 2.549 & 3 & \\
\hline
\end{tabular}




\begin{tabular}{|l|c|c|c|c|c|c|}
\hline H4c & 7.999 & 249 & 0.000 & 3.450 & 3 & \\
H4d & 12.145 & 249 & 0.000 & 2.907 & 3 & \\
\hline H5 & 13.220 & 249 & 0.000 & 3.504 & 3 & Confirmed \\
\hline H6a & 12.145 & 249 & 0.000 & 2.675 & 3 & \multirow{2}{*}{ Confirmed } \\
H6b & 11.380 & 249 & 0.000 & 1.119 & 3 & \\
H6c & 12.300 & 249 & 0.000 & 1.999 & 3 & \\
\hline H7a & 11.290 & 249 & 0.000 & 2.008 & 3 & Confirmed \\
H7b & 11.409 & 249 & 0.000 & 2.487 & 3 & \\
H7c & 10.478 & 249 & 0.000 & 2.897 & 3 & \\
\hline
\end{tabular}

\section{CONCLUSION AND RECOMMENDATIONS}

This innovative research endeavor to propose a unique model for strategic alignment in the financial services with focus on banking sector in Iran. The results of this research show that model of research is extraordinary applicable for actors in the financial services industry. Managers and decision makers should attend to this point that in the strategic implementation process, by using BSC and simultaneous application of its four main dimensions would able to achieve strategic alignment in the organization. By integration all of the organizational resources and in the context of competitive intelligence and dynamic capabilities, it's more easy to gain sustainable Competitive Advantage in the today's turbulent market. Future researchers may develop this model and also investigate the degree of confirmation of this model for other industries.

\section{References}

[1] Aghaei, M.; Vahedi, E.; Safari-Kahreh, M. \& Pirooz, M. (2014). An Examination of the Relationship between Services Marketing Mix and Brand Equity Dimensions. Procedia-Social and Behavioral Sciences, 109, 865-869.

[2] Aghaie, M.; Vahedi, E.; Asadollahi, A. \& Safari-Kahreh, M. (2014). An empirical Investigating to Effects of services Marketing mix on Brand Dimensions in Order to enhance brand Equity in the Tehran's Chain Stores. Research Journal of Recent Sciences, 3(2), 43-60.

[3] Andersen, H. and N. Savic. (2004). Effective quality management through thirdgeneration balanced scorecard. International Journal of Productivity and Performance Management, 53(7), 634-645.

[4] Ayuso, S., Rodriguez, M.A., Ricart, J.E. (2006). Responsible competitiveness at the 'micro' level of the firm - Using stakeholder dialogue as a source for new ideas: a dynamic capability underlying sustainable innovation. Corporate Governance, 6(4), 475-490.

[5] Chen, C. and Jaw, Y. (2009). Building global dynamic capabilities through innovation: A case study of Taiwan's cultural organizations. Journal of Engineering Technological Management, 26, 247-263. 
[6] Fathollahzadeh, M.; Hashemi, A. \& Safari-Kahreh, M. (2011). Designing a New Model for Determining Customer Value Satisfaction and Loyalty towards Banking Sector of Iran. European Journal of Economics, Finance and Administrative Sciences, 28, 126138.

[7] Gupta, P. (2004). Six Sigma Business Scorecard: Ensuring Performance for Profit. New York, McGraw-Hill Professional.

[8] Kangas, J., Kurtila, M., Kajanus, M., Kangas, A. (2003). Evaluating the management strategies of a forestland estate-the S-O-S approach, Journal of Environmental Management, 69, 349-358.

[9] Lawson, B., Samson, D. (2001). Developing innovation capability in organizations: a dynamic capabilities approach. International Journal of Innovation Management, 5 (3), 377-400.

[10] Olascoaga, E. (2008). Dynamic Strategic Alignment: an integrated method. Handbook of Collaborative Management Research, Sage Publications online.

[11] Porter, M.E. (1996). What is Strategy?. Harvard Business Review, 61-78.

[12] Rodriguez, B. (2008). A framework to align strategy, improvement performance, and customer satisfaction using an integration of six sigma and balanced scorecard. A PhD dissertation, Orlando, Florida.

[13] Safari, M. (2015). Customer Lifetime Value to managing marketing strategies in the financial services. International Letters of Social and Humanistic Sciences, 1(2), 164173.

[14] Safari-Kahreh, M. \& Safari-Kahreh, Z. (2012). An Empirical Analysis to Design Enhanced Customer Lifetime Value Based on Customer Loyalty: Evidences from Iranian Banking Sector. Iranian Journal of Management Studies, 5(2), 145-167.

[15] Safari-Kahreh, M.; Ahmadi, H. \& Hashemi, A. (2011). Achieving competitive advantage through empowering employees: An empirical study. Far East Journal of Psychology and Business, 3(3), 26-37.

[16] Safari-Kahreh, M.; Tive, M.; Babania, A. \& Hesan, M. (2014). Analyzing the Applications of Customer Lifetime Value (CLV) based on Benefit Segmentation for the Banking Sector. Procedia-Social and Behavioral Sciences, 109, 590-594.

[17] Safari-Kahreh, Z.; Shirmohammadi, A. \& Safari-Kahreh, M. (2012). An empirical study to analyze customer relationship management strategy using balanced scorecard. Management Science Letters, 2(5), 1603-1612.

[18] Seyed-Javadin, S. R.; Raei, R.; Iravani, M. J. \& Safari, M. (2014). An explanatory analysis to identify and prioritize the challenges of Islamic Banking implementation: the case of IR Iran. International Letters of Social and Humanistic Sciences, 24, 45-55.

[19] Seyed-Javadin, S. R.; Raei, R.; Iravani, M. J. \& Safari, M. (2014). Presenting a conceptual model to explain the role of strategic management and planning in Islamic banking competitiveness. International Letters of Social and Humanistic Sciences, 26, 46-56. 
[20] Seyed-Javadin, S. R.; Raei, R.; Iravani, M. J. \& Safari, M. (2014). Presentation a conceptual model to explain determinants of breakthrough the Islamic banking marketing: a managerial perspective. International Letters of Social and Humanistic Sciences, 28, 58-66.

[21] Seyed-Javadin, S. R.; Raei, R.; Iravani, M. J. \& Safari, M. (2014). Conceptualizing and Examining the Critical Success Factors for Implementing Islamic Banking System towards Banking Sector of Iran: a Mixed Method Approach. Iranian Journal of Management Studies, Article in press; available at: http://ijms.ut.ac.ir.

[22] Teece, D.; Pisano, G. \& Shuen, A. (1997). Dynamic capabilities and strategic management. Strategic Management Journal. 18, 509-34.

[23] Thompson S.H. \& Teo, Wing Y. C. (2001). Assessing the impact of using the Internet for competitive intelligence. Information \& Management, 39(1), 67-83.

[24] Yuksel, I., Dagdeviren, M. (2007). Using the analytic network process (ANP) in a SWOT analysis - a case study for a textile firm. Information Science, 177(16), 33643382. 